\title{
Diagnosis, treatment, and rehabilitation of a patient with inflammatory pseudotumor
}

\author{
Flávio Tendolo Fayad ${ }^{1}$, Matheus Cavalcante Tomaz Bezerra ${ }^{2}$, \\ Marina Rolo Pinheiro da Rosa ${ }^{1}$, Tiago Novaes Pinheiro ${ }^{3}$
}

Correspondence: Dr. Matheus Cavalcante Tomaz Bezerra

Email: matheusbezerra_tomaz@hotmail.com

\author{
'Department of Surgery, State University of Amazonas, \\ Manaus, AM, Brazil, \\ ${ }^{2}$ Department of Surgery, Federal University of \\ Amazonas, Manaus, AM, Brazil, \\ ${ }^{3}$ Department of Pathology, State University of \\ Amazonas, Manaus, AM, Brazil
}

\begin{abstract}
Inflammatory pseudotumors are a group of lesions of unknown etiology that mimic clinically and radiographically neoplasms. In the maxilla, inflammatory pseudotumors are presented with bone alterations of erosion, remodeling, and sclerosis. The diagnosis is of exclusion, where multiple biopsies are required. The present study aims to report the case of a male patient who presented with increased volume in the left maxillary region, with diagnosis after total left maxillectomy being inflammatory pseudotumor. The patient did not present recurrences with 3 years of preservation and underwent by multidisciplinary treatment with esthetic and functional rehabilitation with the preparation of a bucomaxilo prosthesis. Despite presenting some suggestive clinical features, the inflammatory pseudotumor has a difficult and of exclusion diagnosis, where multiple biopsies are required. They are lesions that simulate clinically and radiographically neoplasms. If it is surgically accessible, the treatment of choice is complete surgical resection.
\end{abstract}

Key words: Inflammatory pseudotumor, maxillectomy, oral surgery

\section{INTRODUCTION}

Inflammatory pseudotumors are a group of lesions that mimic neoplasms clinically and radiographically. ${ }^{[1]}$ They are expansive and uncommon lesions of unknown etiology that mainly affect the lungs and orbits. ${ }^{[2]}$ In the maxilla, inflammatory pseudotumors have been reported with bone alterations of erosion, remodeling, and sclerosis. ${ }^{[3]}$

Diagnosis is difficult and of exclusion, where multiple biopsies are often necessary..$^{[3,4]}$ Several complementary examinations may be required, such as computed tomography (CT) and bone scintigraphy.

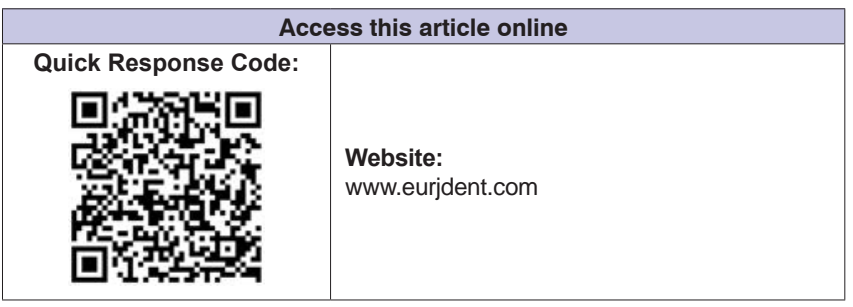

Histopathological analysis plays a key role in its diagnosis. ${ }^{[3]}$

Histologically, it has a nonspecific appearance with two characteristic cell types: myofibroblasts and inflammatory cells. ${ }^{[3]}$ Due to its diverse histological presentations, it has several definitions, such as inflammatory myofibroblastic tumor and myofibroblastoma. ${ }^{[3]}$

If it is surgically accessible, the treatment of choice is complete surgical resection. ${ }^{[5,6]}$ Radiotherapy is

This is an open ae $s$ joumal, and artik es are dit ributed under the terms of the Creative Commons Attribution-NonCommercial-ShareAlike 4.0 License, whib allows others to remix tweak and build upon the work non-o mmeri ally, as long as appropriate $\mathrm{c}$ edit is gie $\mathrm{n}$ and the new $\mathrm{c}$ eations are lie $\mathrm{n} \boldsymbol{\mathrm { e }} \mathrm{d}$ under the identia I terms

For reprints contact: reprint@ medk ow.o m

How to cite this article: Fayad FT, Tomaz Bez ra MC, Pinheiro da Ros MR, Pinheiro TN. Diagnosis treatment, and rehabilitation of a patient with inflammatory pseudotumor. Eur J Dent 2018;12:454-8.

DOI: 10.4103/ejd.ejd_333_17 
reserved for selected cases and chemotherapy is not found to be effective. ${ }^{[6]}$

In this study, it was reported the case of an inflammatory pseudotumor in the left maxilla, which treatment was total surgical resection associated with postoperative rehabilitation with bucomaxillary prosthesis.

\section{CASE REPORT}

A 34-year-old male patient was admitted to the Oral and Maxillofacial Surgery Service of the Adriano Jorge Hospital with a history of increased volume in the left infraorbital region [Figure 1] and painful complaint. At the physical examination, a firm, palpable, sessile, adherent nodule with a slow evolution of about 2 years was observed.

Puncture had a negative result. An incisional biopsy of the lesion was performed under local anesthesia [Figure 2], where it was obtained a suggestive diagnosis of malignant schwannoma.

After requesting complementary examinations of bone scintigraphy and CT [Figures 3 and 4], extensive bone remodeling was observed in the left maxilla. Due to the clinical characteristics and histopathological examination suggestive of a malignant tumor and in combination with the findings of the complementary examinations, total left maxillectomy was performed by Weber Ferguson access under general anesthesia and orotracheal intubation [Figures 5-7]. The surgical specimen was sent for histopathological analysis.

Histopathological examination showed densely collagenous connective tissue infiltrated by a great number of large pleomorphic, sometimes multinucleated, histiocytoid cells with nuclei of varying sizes. Fragments of bone tissue were also observed with innumerable areas of active resorption [Figure 8].

The patient is about 3 years of preservation and underwent multidisciplinary treatment with the manufacture of bucomaxillary prosthesis and awaits new surgery for rehabilitation [Figures 9-14].

\section{DISCUSSION}

Inflammatory pseudotumors do not present an identifiable common cause, but some authors believe that any inflammatory stimulus can trigger it. ${ }^{[1,7,8]}$ It has been postulated that they may be the result of a postinflammatory repair process, a metabolic disorder, or an antigen-antibody interaction with

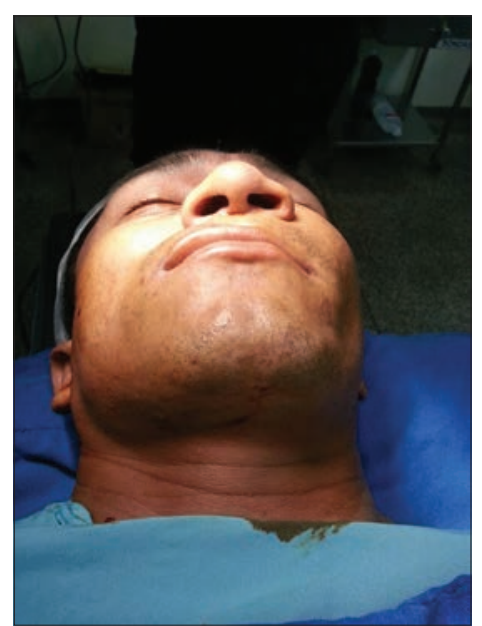

Figure 1: Increased volume in the left infraorbital region

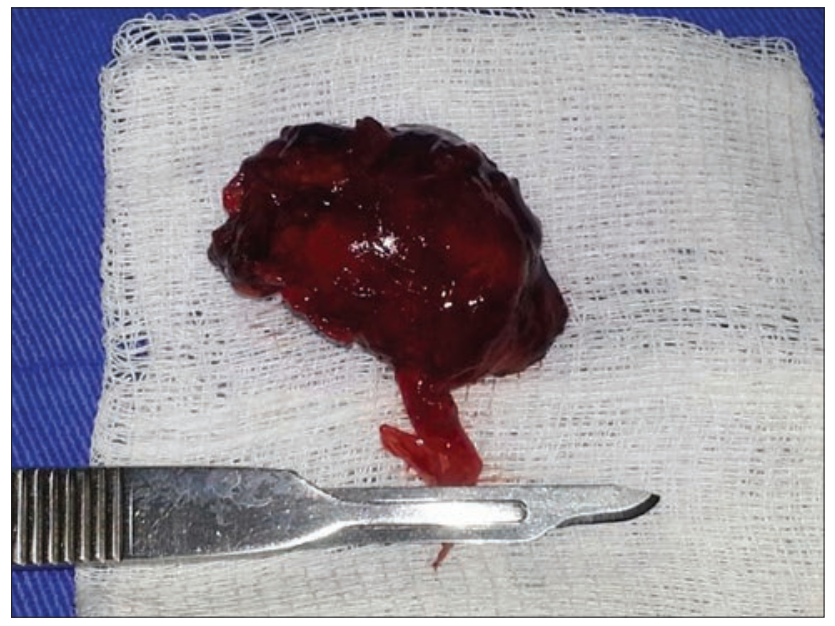

Figure 2: Incisional biopsy adhered to the infraorbital nerve

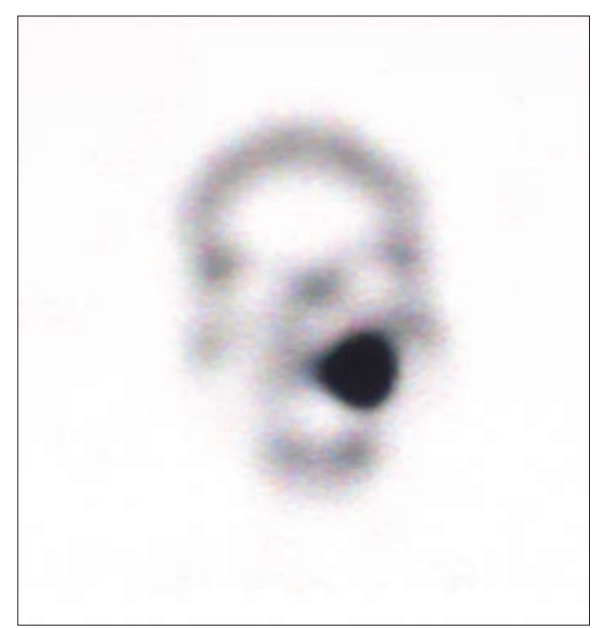

Figure 3: Bone scintigraphy showing remodeling of the bone

an agent that was no longer identified in aspiration or biopsy material. ${ }^{[8]}$ In the present study, it was not possible to observe a triggering process for its development, confirming an uncertain etiology. 
Fayad, et al.: Inflammatory pseudotumor of the maxilla

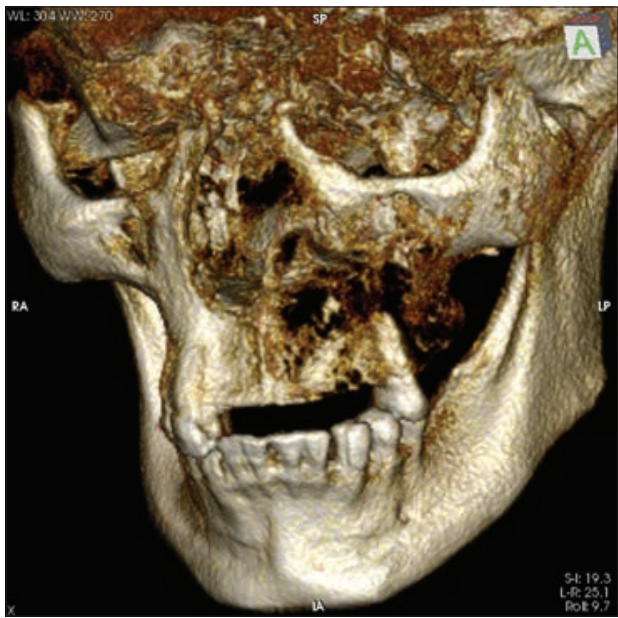

Figure 4: Computed tomography of the face

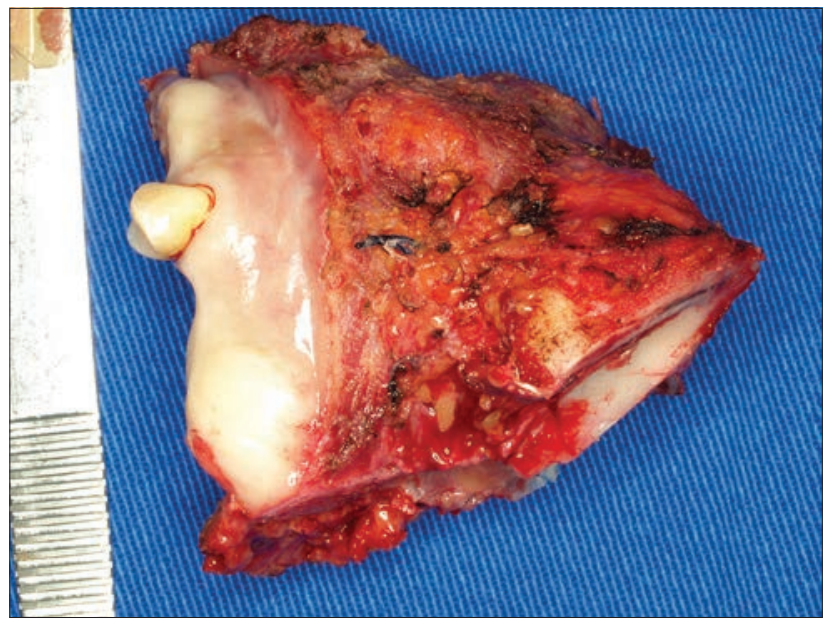

Figure 6: Surgical specimen of the left maxillectomy

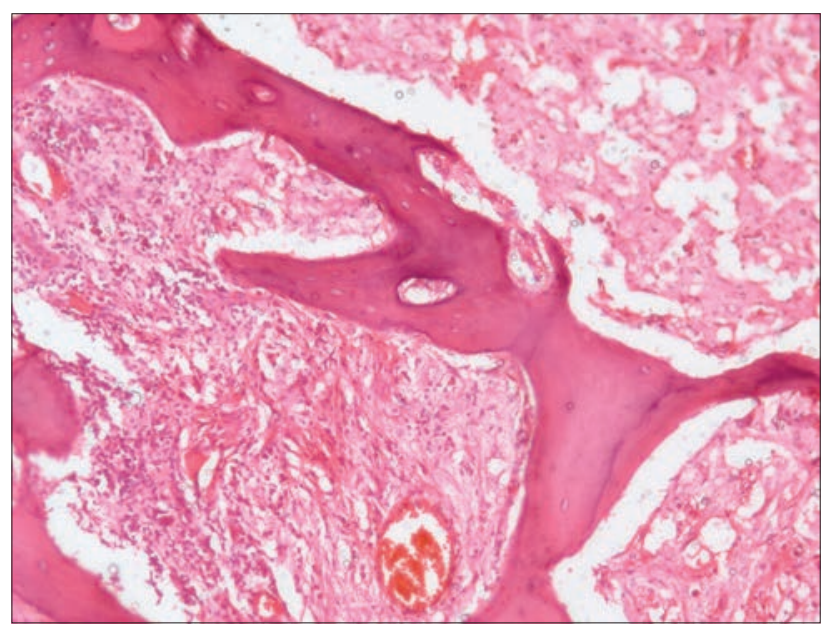

Figure 8: Bone resorption and connective tissue infiltration

They have this denomination because they are lesions that simulate neoplasms clinically and radiographically. ${ }^{[1-3]}$ Regarding the radiographic aspects, they have a more aggressive appearance in

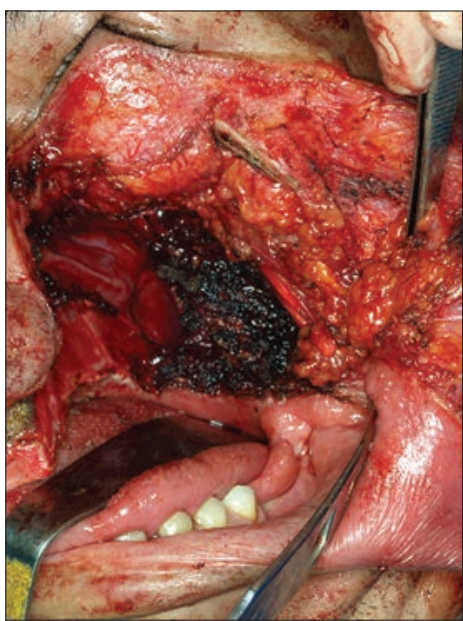

Figure 5: Initial aspect after total maxillectomy

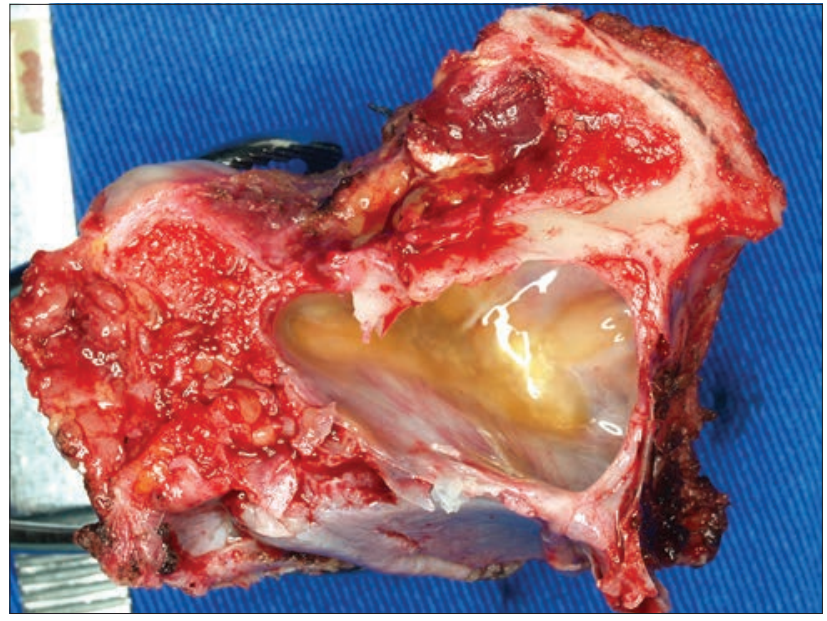

Figure 7: Integrity of the maxillary sinus

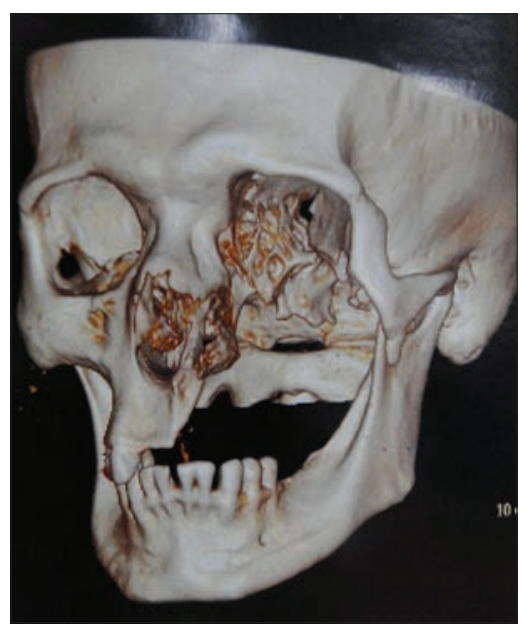

Figure 9: Computed tomography 2 years after the procedure

the maxilla than orbital tumors with bone alterations such as erosion, remodeling, and sclerosis. ${ }^{[9-11]}$ After image examination, a pattern of bone alteration was obtained according to the literature. 


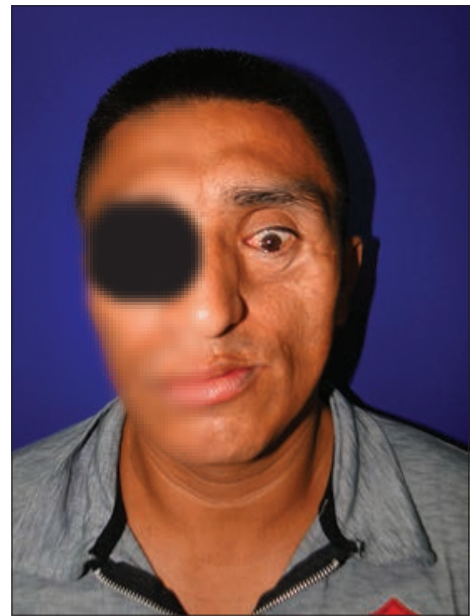

Figure 10: Postoperative aspect of 2 years

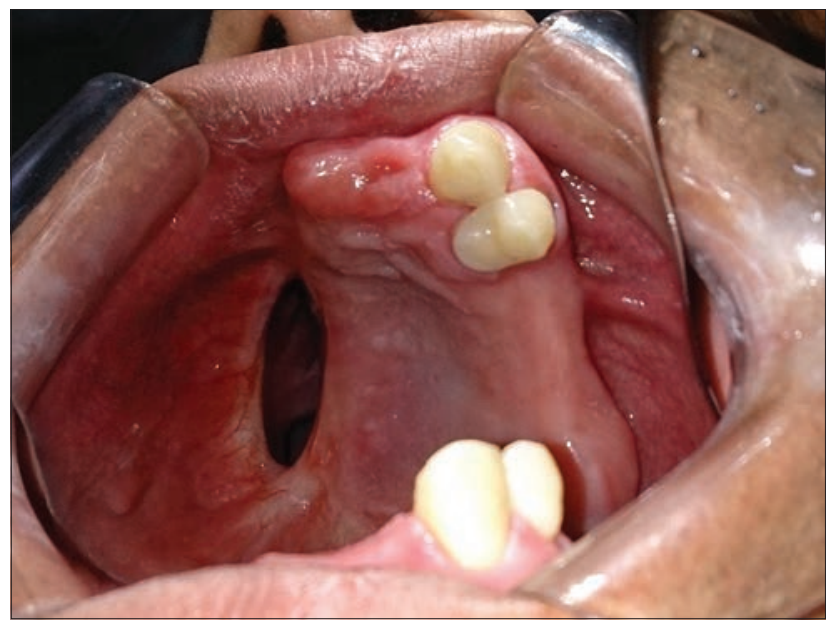

Figure 12: Intraoral aspect of 2 years

It is reported as occurring in almost every site of the body, most commonly involving the lungs. When it occurs in the head and neck, it has been reported affecting mainly the orbits and, rarely, the maxillary sinus. ${ }^{[2]}$ However, in this study, after the total left maxillary procedure, it was possible to observe maxillary sinus integrity, suggesting a different location from the most prevalent.

Due to their widespectrum of histological presentations, they present several synonyms such as histiocytoma and xanthogranuloma. ${ }^{[3,12,13]}$ The histological aspect is nonspecific, with two characteristic cell types: myofibroblasts and inflammatory cells. Temporal progression from acute to chronic inflammation to a fibrous process has been observed. ${ }^{[14,15]}$ It was possible to observe a large cellular pleomorphism associated with areas of bone resorption.

Viegneswaran et al., ${ }^{[1]}$ in a literature review of 28 cases of inflammatory pseudotumor of the oral cavity and

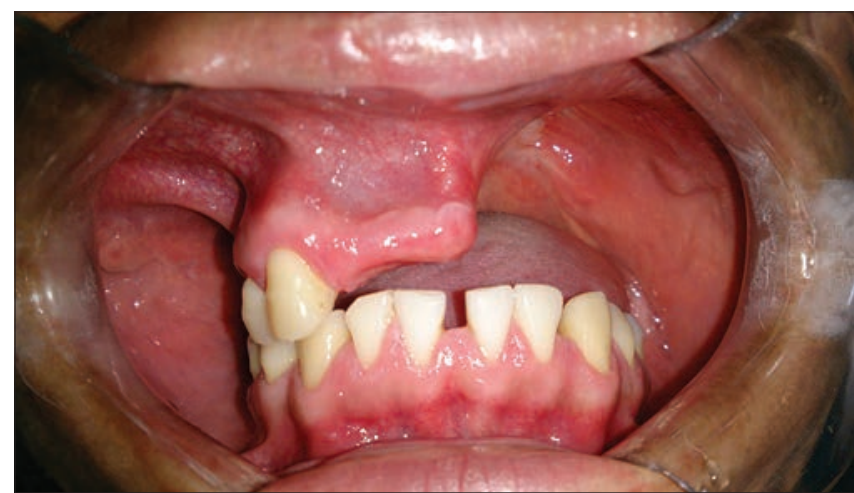

Figure 11: Frontal view of intraoral aspect after 2 years of follow-up

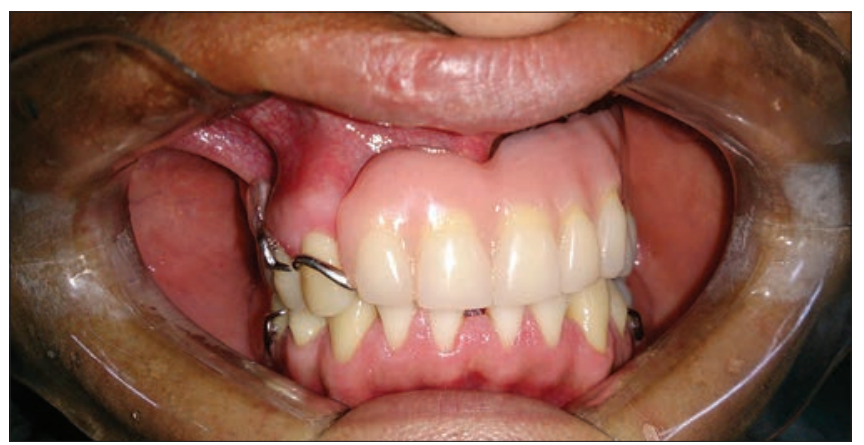

Figure 13: Bucomaxillary prosthesis providing rehabilitation

maxillary sinus, reported a 1.5:1 of male: female ratio and mean age of presentation of 33 years. In this report, it was possible to observe a 34-year-old male patient, with an age of presentation corresponding to their study.

Some laboratory abnormalities may be observed, such as hypochromic microcytic anemia, thrombocytosis, and elevated erythrocyte sedimentation rate, which disappear after surgical resection. ${ }^{[14]}$ Systemic symptoms are generally not found..$^{[3,13]}$ The patient did not present alterations in blood count or systemic symptoms.

Corticosteroids and surgical resection are the mainstays of therapy for inflammatory pseudotumors of the head and neck. High-dose corticosteroids cause rapid decrease of inflammatory pseudotumor, but tumors recurred in $20 \%$ of patients with parapharyngeal space or skull base treated with corticosteroids..$^{[5,6]}$ Radiotherapy is reserved for selected cases, since their success is limited and has the potential to induce malignancy in a benign lesion. ${ }^{[13]}$ Chemotherapy was not found to be effective. ${ }^{[6]}$ In our case, due to inconclusive results obtained with previous examinations, we opted for complete surgical resection through total left maxillary colectomy to establish the diagnosis. Corticosteroids were not used since there was complete excision of the lesion. 
Fayad, et al.: Inflammatory pseudotumor of the maxilla

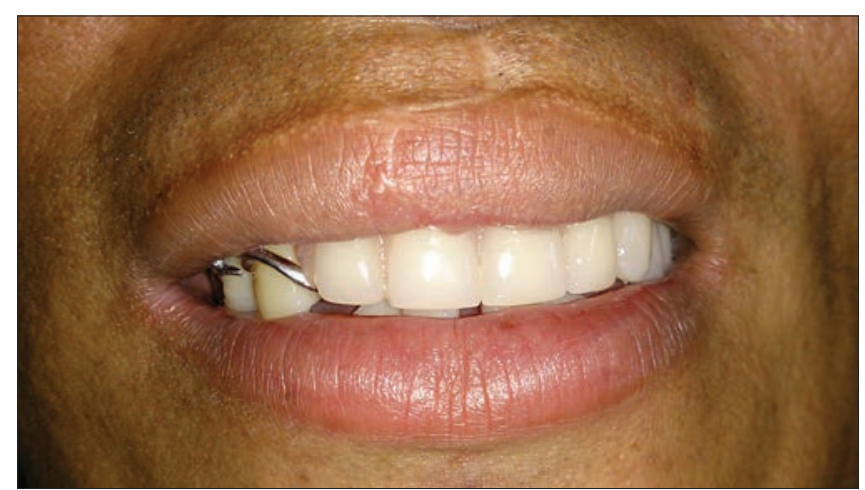

Figure 14: Smile with the prosthesis in function

The inflammatory pseudotumor is a lesion that simulates neoplasms clinically and radiographically, of unknown etiology, that mainly affects lungs and orbits. It has a difficult diagnosis, with the frequent need of multiple biopsies to establish it, making a diagnosis of exclusion. It is necessary for the surgeon a certain knowledge of the characteristics of this unusual lesion, due to its very controversial and comprehensive characteristics. When surgically accessible, the treatment of choice is complete surgical resection.

\section{Declaration of patient consent}

The authors certify that they have obtained all appropriate patient consent forms. In the form the patient(s) has/have given his/her/their consent for his/her/their images and other clinical information to be reported in the journal. The patients understand that their names and initials will not be published and due efforts will be made to conceal their identity, but anonymity cannot be guaranteed.

\section{Financial support and sponsorship}

Nil.

\section{Conflicts of interest}

There are no conflicts of interest.

\section{REFERENCES}

1. Viegneswaran N, Bailey W, Tilashalski K. Inflammatory myofibroblastic tumor (inflammatory pseudotumor) of the maxilla: Clinicopathologic features of a case and review of the current literature. Oral Surg Oral Med Oral Pathol Oral Radiol Endod 1997;84:190-1.

2. Agarwal A. Orbital pseudotumor: Diagnosis on fine needle aspiration cytology. J Cytol 2010;25:67-9.

3. Som PM, Brandwein MS, Maldjian C, Reino AJ, Lawson W. Inflammatory pseudotumor of the maxillary sinus: CT and MR findings in six cases. AJR Am J Roentgenol 1994;163:689-92.

4. Zerilli TC, Burke CL. Orbital pseudotumor after an upper respiratory infection: A comprehensive review. Optometry 2010;81:638-46.

5. Cherukupally SR, Mankarious LA, Faquin W, Cunningham MJ. Pediatric non-orbital pseudotumor of the head and neck. Int J Pediatr Otorhinolaryngol 2003;67:649-53.

6. Maruya S, Miura K, Tada Y, Masubuchi T, Nakamura N, Fushimi C, et al. Inflammatory pseudotumor of the parapharyngeal space: A case report. Auris Nasus Larynx 2010;37:397-400.

7. Weisman RA, Osguthorpe JD. Pseudotumor of the head and neck masquerading as neoplasia. Laryngoscope 1988;98:610-4.

8. Restrepo S, Mastrogiovanni LP, Palacios E. Inflammatory pseudotumor of the trachea. Ear Nose Throat J 2003;82:510-2.

9. De Vuysere S, Hermans R, Sciot R, Crevits I, Marchal G. Extraorbital inflammatory pseudotumor of the head and neck: CT and MR findings in three patients. AJNR Am J Neuroradiol 1999;20:1133-9.

10. Takimoto T, Kathoh T, Ohmura T, Kamide M, Nishimura T, Umeda A. Inflammatory pseudotumor of the maxillary sinus mimicking malignancy. Rhinology 1990;28:123-7.

11. Garcia FM, Aiguabella MA, Liesa RF, Esteban JA, Asenio RM, Gonzalez EA. Inflammatory Pseudotumor of paranasal sinuses. Acta Otorrinolaringol Esp 1990;41:351-3.

12. Batsakis JG, el-Naggar AK, Luna MA, Goepfert H. "Inflammatory pseudotumor": What is it? How does it behave? Ann Otol Rhinol Laryngol 1995;104:329-31.

13. Ruaux C, Noret P, Godey B. Inflammatory pseudotumour of the nasal cavity and sinuses. J Laryngol Otol 2001;115:563-6.

14. Tang TT, Segura AD, Oechler HW, Harb JM, Adair SE, Gregg DC, et al. Inflammatory myofibrohistiocytic proliferation simulating sarcoma in children. Cancer 1990;65:1626-34.

15. West SG, Pittman DL, Coggin JT. Intracranial plasma cell granuloma. Cancer 1980;46:330-5. 